\title{
Future Challenges for Family Medicine Education Research
}

Arch G. Mainous III, PhD

(Fam Med. 2022;54(3):173-5.)

doi: 10.22454/FamMed.2022.755008

D uring my 15 years on the editorial team at Family Medicine (12 years as deputy editor and 3 years as associate editor), I have seen many predictions of the future challenges for family medicine education. Some actually became big things, and some just fizzled out.

What makes for a successful prediction of future challenges? Many of these forecasts arise from task force or expert panel reports, but sometimes they just arise from a commentator's speculation. Many of these predictions are intertwined with preexisting beliefs regarding what the authors hope will happen. Typically, the most successful predictions are variations of natural experiments based on environmental, technological, or regulatory changes. It seems useful and fun to speculate on where things are going and the implications of successfully integrating or dealing with those future challenges. Readers can then revisit them in 10 years and assess their accuracy.

\section{Selecting Residents in an Age of Pass/Fail Assessments}

Decisions on candidates for residency slots are based on several variables including performance in medical school, the dean's letter, specialty interest and personal statement, authorship of peer-reviewed publications, and performance on the United States Medical Licensing Examination (USMLE) Step 1 and Step 2 Exams. ${ }^{1,2}$ Many medical schools have transitioned to pass/fail or pass/fail/honors grading systems and away from letter grades. In addition, Step 1 scores, which have historically played a major role in ranking residency applicants, have moved to pass/fail. ${ }^{3,4}$ A 2018 survey found that $94 \%$ of program directors use Step 1 scores to screen applicants for residency interviews. ${ }^{1}$ Substantial discussion has focused on the unintended consequences of this change. ${ }^{5-7}$ With $94 \%$ of US medical students passing Step 1 on the first attempt and no scores, programs will look for other measures of achievement to distinguish applicants.

In a survey of program directors of Accreditation Council of Graduate Medical Education (ACGME)-accredited residency programs in 30 specialties $(n=2,095)$, only $15.3 \%$ of program directors agreed with changing Step 1 to pass/fail, and $77.2 \%$ expect this change to make objective comparison of applicants more difficult. ${ }^{8}$ With no grades, class rank, or Step 1 scores, how will students show that they are competitive candidates?

\section{Essential Research on This Issue}

We will need to know the unintended consequences of this change on the behavior of both medical students and residency directors. Moreover, we will need to specifically explore the performance of the new crop of residents in this environment where they are matched based only on subjective criteria. This will require examining both medical knowledge and the ACGME Milestones, since they are only moderately correlated. ${ }^{9}$

From the Department of Health Services Research, Management and Policy, and Department of Community Health and Family Medicine, University of Florida, Gainesville, FL. 


\section{Teaching How to Provide Care in a Virtual Environment}

The COVID-19 pandemic had a huge impact on the delivery of education from elementary school through high school to college, medical school, and residency. Because of social distancing, educators adapted to deliver education in a virtual format. Classrooms became Zoom rooms where the teachers and students were all connected into online virtual groups. This change has affected family medicine education at both the medical student and residency level. Furthermore, the pandemic resulted in the rapid implementation of telehealth interactions to allow continued access to care while reducing public health risks. ${ }^{10}$ This accelerated the change in reimbursement for telehealth services by the Centers for Medicare and Medicaid Services. ${ }^{11}$ The share of Medicare visits conducted through telehealth in 2020 increased from approximately 840,000 in 2019 to 52.7 million. ${ }^{12}$

Clearly, the delivery of primary care through telehealth is happening. Moreover, some insurers and health systems are implementing plans for patients to receive longitudinal care from telehealth-only physicians for most of their primary care needs. ${ }^{13}$ The challenge that this presents to family medicine educators is how to train physicians to successfully treat patients in a completely new paradigm, particularly one without a physical exam.

\section{Essential Research on This Issue}

We need to know whether important problems are missed by following protocols and in environments that do not include physical exams or face-to-face interactions. Since family medicine plays the important role of first-contact care, it will be necessary to evaluate whether decisions on differential diagnoses are inappropriately constricted because of the limited amount of data available to the physician.

\section{Consistency Between Scope of Practice Training and Actual Practice}

A key concern in the training of family physicians is the linkage between curriculum and the practices of family physicians after training is completed. Although opinion leaders in academic family medicine continue to argue for a broad scope of practice in training and a corresponding assessment by the American Board of Family Medicine (ABFM), there is some indication that most family physicians in practice have a much narrower scope of practice than the idealized family physician. ${ }^{14,15}$
For example, training in obstetric care is a feature of full-scope family medicine training, yet when comparing initial certifiers to the ABFM examination regarding their intention to practice obstetrics, only a small minority voiced an intention $(23.7 \%)$, and those individuals out in practice had an even smaller group who were actually doing obstetric care $(7.7 \%){ }^{15}$ The underlying reason for the disconnect between the curriculum and the actual practice could be lifestyle considerations, ability to perform those services as employed physicians, a lack of interest, or a combination of these and other factors. However, it is clear that there is a disconnect. Making the curriculum relevant to actual practice so that graduates of family medicine residencies are learning what they need to know is a challenge that will need to become a priority.

\section{Where We Need to Go With Research on This Issue}

Competing demands inherent in this issue are the health needs of the community served by the family physician and the practice interests of the family physician. This tension builds off of the free market system for creating a health workforce in the United States, with physician specialties treating medical students and residents as customers to which specialties and residencies are marketing an attractive experience. Research is needed to determine how popular family medicine as a specialty will be to medical students if aspects of the scope of practice training are not popular (eg, doesn't emphasize a controlled lifestyle), and more importantly, what the population health outcomes will be for communities with family physicians. What role does family medicine need to play in underserved and rural areas?

\section{Conclusions}

In conclusion, only time will tell how significantly these future challenges impact family medicine education. The environment is dynamic, so any changes will need to be nimble and flexible. Who predicted COVID-19 and its associated implications? Any change related to these identified issues will also have unintended consequences. Most importantly, the question will be, "What is the role of family medicine in the future health system, and what will family medicine look like?" Will the role of the family physician be to triage a narrow scope of conditions in a digital interface to then send patients on to subspecialists? Will the role be something broader, and what part 
can family medicine play in the redesign of the health system? That said, it is better to think ahead and be proactive than to be reactive to events and changes that could have been predicted.

ACKNOWLEDGMENTS: I would like to thank Peter Carek, MD, MS, Maribeth Williams, MD, MSCR, and Amy Blue, $\mathrm{PhD}$, for their thoughts on these subjects. I have discussed all of these issues with them, and they have helped me focus my thinking.

CORRESPONDENCE: Address correspondence to Dr Arch G. Mainous III, Department of Community Health and Family Medicine, University of Florida, Health Sciences Center, PO Box 100237. Gainesville, FL. 352-273-6073. arch.mainous@ufl.edu.

\section{References}

1. Results of the 2018 NRMP Program Director Survey. National Resident Matching Program. Accessed January 10 2022. https://www.nrmp.org/wp-content/uploads/2018/07/ NRMP-2018-Program-Director-Survey-for-WWW.pdf.

2. Hartman ND, Lefebvre CW, Manthey DE. A narrative review of the evidence supporting factors used by residency program directors to select applicants for interviews. J Grad Med Educ. 2019;11(3):268-273. doi:10.4300/JGME-D-18-00979.3

3. Gauer JL, Jackson JB. The association of USMLE Step 1 and Step 2 CK scores with residency match specialty and location. Med Educ Online. 2017;22(1):1358579. doi:10.1080 /10872981.2017.1358579

4. USMLE Step 1 transition to pass/fail only score reporting. United States Medical Licensing Examinations. Accessed January 10, 2022. https://www.usmle.org/usmle-step-1-transition-passfail-only-score-reporting

5. Crane MA, Chang HA, Azamfirei R. Medical education takes a step in the right direction: where does that leave students? JAMA. 2020;323(20):2013-2014. doi:10.1001/jama.2020.2950

6. Humphrey HJ, Woodruff JN. The pass/fail decision for USMLE Step 1-next steps. JAMA. 2020;323(20):2022-2023. doi:10.1001/jama.2020.3938
7. Salari S, Deng F. A stepping stone toward necessary change: how the new USMLE Step 1 scoring system could affect the residency application process. Acad Med. 2020;95(9):13121314. doi:10.1097/ACM.0000000000003501

8. Makhoul AT, Pontell ME, Ganesh Kumar N, Drolet BC. Objective measures needed - program directors' perspectives on a pass/fail USMLE Step 1. N Engl J Med. 2020;382(25):23892392. doi:10.1056/NEJMp2006148

9. Mainous AG III, Fang B, Peterson LE. Competency assessment in family medicine residency: observations, knowledgebased examinations, and advancement. J Grad Med Educ. 2017;9(6):730-734. doi:10.4300/JGME-D-17-00212.1

10. Mann DM, Chen J, Chunara R, Testa PA, Nov O. COVID-19 transforms health care through telemedicine: evidence from the field. J Am Med Inform Assoc. 2020;27(7):1132-1135. doi:10.1093/jamia/ocaa072

11. Medicare Telemedicine Health Care Provider Fact Sheet. Centers for Medicare \& Medicaid Services. March 17, 2020. Accessed January 10, 2022. https://www.cms.gov/newsroom/ fact-sheets/medicare-telemedicine-health-care-provider-factsheet

12. New HHS Study Shows 63-Fold Increase in Medicare Telehealth Utilization During the Pandemic. Centers for Medicare \& Medicaid Services Newsroom. December 3, 2021. Accessed January 10, 2022. https://www.cms.gov/newsroom/ press-releases/new-hhs-study-shows-63-fold-increase-medicare-telehealth-utilization-during-pandemic

13. Whitehead DC, Mehrotra A. The growing phenomenon of "virtual-first" primary care. JAMA. 2021;326(23):2365-2366. doi:10.1001/jama.2021.21169

14. National Graduate Survey for year(s): 2020. American Board of Family Medicine (ABFM). Accessed February 4, 2022 https://www.theabfm.org/sites/default/files/PDF/Nationa1Only_Report2020.pdf

15. Coutinho AJ, Cochrane A, Stelter K, Phillips RL Jr, Peterson LE. Comparison of intended scope of practice for family medicine residents with reported scope of practice among practicing family physicians. JAMA. 2015;314(22):2364-2372. doi:10.1001/jama.2015.13734 